XUELEI MENG, Ph.D.1,2

(Corresponding author)

E-mail: mxl@mail.Izjtu.cn

LIMIN JIA, Ph.D. ${ }^{2}$

E-mail: jialm_skl@163.com

WANLI XIANG, Ph.D. ${ }^{1}$

${ }^{1}$ School of Traffic and Transportation, Lanzhou Jiaotong

University, P.O. Box 405, No. 88, Anning West Road,

Anning District, Lanzhou, Gansu 730070, China

2 State Key Laboratory of Rail Traffic Control and Safety

Beijing Jiaotong University, No. 3, Shangyuancun,

Haidian District, Beijing 100044, China
Traffic Planning

Original Scientific Paper

Submitted: 29 Aug. 2017

Accepted: 10 July 2018

\title{
A PETRI NET MODEL OF TRAIN OPERATION SIMULATION FOR HARMONIZING TRAIN TIMETABLES OF NEIGHBOR DISPATCHING SECTIONS
}

\begin{abstract}
Train timetable is the key document to regulate railway traffic through sequencing train movements to keep the appropriate order. Timetable stability and on-schedule rate are closely related. Delays caused by disturbances in train operations can be absorbed by a high quality timetable with high stability, and the on-schedule rate then can be assured. This paper improves the stability of timetables of several connected railway sections to assure the on-schedule rate with a simulation method. Firstly, we build a macroscopic network model of train operation in a railway network using the Petri net theory. Then we design the train tracking subnet model, the station subnet model and arrival-departure track subnet model. At last we propose a computing case, simulating the train operation process based on the presented models, and the simulation results prove the feasibility and availability of the models. The approach presented in this paper can offer valuable decision-support information for railway operators preparing train timetables.
\end{abstract}

\section{KEY WORDS}

train operation; Petri net; simulation; neighbor dispatching section;

\section{INTRODUCTION}

With the rapid growth of high-speed railway operating length in China, railway operations are becoming increasingly difficult. Railway operators must optimize their working plans to deal with the hard work on a complex railway network. Train timetable is the key document to regulate railway traffic through sequencing train movements to keep the appropriate order. Therefore, high quality timetables and effective real-time dispatching play an important role in this context. Yet, what is a high quality timetable? The essence of a timetable is to decide the inbound and outbound times of trains at the stations that they will pass.. However, it is more than that. The inbound and outbound times of trains are the basis of train dwelling times at stations, the running times in the sections between stations, the buffer times at the station and in the running section. Such indirect elements buried in the timetable are the actual decisive factors of timetable quality, affecting the operation recovery ability according to the timetable of the railway transportation system.

Usually, each timetable is designed for a certain dispatching railway section. The timetabling work is affected by the existing timetable of a neighbor section, or, we can say, the timetabling operations of neighbor sections affect each other. Therefore, it is quite necessary to harmonize the train timetables of neighbor dispatching sections.

Currently, there are plenty publications on train timetable optimization problems. The majority of the publications are mathematical approaches to generating or optimizing the timetable, with linear or nonlinear programming models. In addition, an important timetable optimization method is the train simulation method. It relies on the computing speed of computers to simulate the train operation process many times so as to select an optimized timetable according to the simulation results. A common modeling method is based on the Petri net theory.

With the development of high speed railway, the topology structure of the railway network has changed greatly in China. The number of dispatching sections is growing, and more and more trains are required to run from one section to another. Intersection stations play an important role in receiving and dispatching trains. However, the number of arrival-departure tracks in a station is limited. The timetables of connected sections may be infeasible if too many trains pass an 
intersection station, especially when a disturbance occurs. Therefore, it is necessary to study the problem of harmonizing train timetables of neighbor dispatching sections to assure timetable feasibility.

The structure of the paper is as follows. First, Section 2 presents a literature review on train operation simulation. Section 3 constructs a macroscopic simulation model and three subnet simulation models using the Petri net theory. Section 4 presents a computing case and an analysis of the computing results. Finally, Section 5 draws the conclusion.

\section{LITERATURE REVIEW}

There are numerous publications on train operation simulation today. Keijia et al. formulated a train operation simulation model which reproduced the behavior of train operations taking into account the interactions between trains [1]. Flynn et al. presented a detached-eddy simulation model to simulate freight train movement and generate higher slipstream velocities, which was an innovative method to improve railway capacity [2]. Mihailovs et al. proposed a simulation model for studying the interaction of a railway station and harbor to improve the quality of daily operations [3] Warg et al. presented a simulation method for evaluation of timetables based on capacity and economic assessment [4]. Debois et al. designed a simulation tool for domain experts to analyze and rehearse emergency response plans, which resulted in a flexible model giving rehearsal participants the freedom to explore different ways to proceed [5]. Nagel and Schreckenberg firstly constructed a cellular automaton model to simulate freeway traffic called the NS model [6]. Spyropoulou employed the cellular automata model to model a signal controlled stream [7]. Kheldoun et al. proposed a formal semantics of Business Process Modeling Notation (BPMN) using recursive ECATNets, based on high-level Petri nets [8]. These publications employed the simulation approach to study the train operation issues, proving that it is an ideal method.

The Petri net theory has been used in train operation modeling for a long time. Wang et al. put forward a colored Petri nets based workload evaluation model, validated with Multi-Attribute Task Battery-II [9]. Pachpor et al. demonstrated the use of Petri nets in a workshop setup to improve machine utilization [10]. Milinković et al. proposed a fuzzy Petri net model to estimate train delays, which had the characteristics of hierarchy, color, and time [11]. Ahmad and Khan used an arc-constant colored Petri net (ac-CPN) to construct a train flow subnet, while the monitors were modeled using the place/transition net [12]. Boudi et al. presented a methodology of place/transition Petri nets transformation into $B$ abstract machines enabling an interesting combination of the graphical modeling power of Petri nets and the verification tools of the $B$ method [13]. Khan et al. employed the Petri net model to reduce the existing two-dimensional controls along the switch and level crossing to one-dimensional for shifting it to a train only [14]. Ricci described an extended research activity on the formalization of railway operation with Petri nets, including a large set of operational phases in railway traffic [15]. Basile et al. used a modified state class graph, which was introduced for the marking estimation of labeled timed Petri net systems, to analyze the properties of labeled timed Petri net systems [16]. Kaakai et al. presented a simulation model based on hybrid Petri nets able to help transit authorities in performance evaluation procedures aimed to prevent railway accidents [17]. Quiroga et al. proposed a Petri net based modeling method for the Monte Carlo simulation for railway infrastructure diagnosis work [18]. Marrone et al. provided a joint application of two model-driven techniques for physical and cyber-security evaluation [19]. Wang et al. built a train rescheduling model based on Petri nets and heuristic sear and proposed a conflict resolution algorithm to solve the model [20]. Durmuş et al. employed a hybrid modeling technique known as batches Petri nets to model the movement process of two consecutive trains as moving-blocks on a single railway line [21]. The publications above proved that the Petri net theory is suitable to build the simulation model for train operation, which we also use in this paper.

There are also some publications on train timetables and robustness. Goverde studied train timetable stability based on the max-plus algebra theory [22]. Delorme et al. presented a module for evaluating timetable stability, which employed an innovative method based on delay propagation and using shortest path problem resolution [23]. Engelhardt-Funke and Kolonko derived a cost-benefit analysis of investments, where the benefit was measured in reduced waiting time for passengers changing lines. They analyzed the impact that an increasing synchronization of the timetable had on its stability. They used sophisticated adaptive evolutionary algorithms to solve the problem [24]. Niu et al. proposed a nonlinear integer programming model to optimize the train timetable to reduce the waiting times of passengers. It brought forward a method to improve the robustness of the timetable [25]. Hansen linked station capacity with the stability of train operations. He estimated the amount of train waiting time due to conflicting claims of routes at a station in case of delays by means of both queuing theory and a max-plus algebra approach [26]. Cicerone et al. studied a method to deal with a single delay in train operation. They put forward polynomial algorithms for special cases [27]. Liebchen and Stille proposed an approach for timetabling to resist the delays [28]. D'Angelo et al. proposed an algorithmic approach on trees to generate recoverable robust timetables [29]. Cicerone et al. extended the concept of recoverable 
robustness to deal with many recovery steps and introduced the new notion of multi-stage recoverable robustness [30]. The dynamic characteristic has been studied for about twenty years, and it is still a hot topic in the research field of train operations.

All these publications gave us much enlightenment when we studied train timetable optimization at the side of dynamic characteristic improvement, especially timetable stability. In this paper, we build a Petri net model to repeatedly simulate train operation and obtain a large number of feasible timetables within a certain probability of disturbance. Then we choose the best one to be applied, according to the concerned indexes. The goal is to harmonize train timetables of neighbor dispatching sections and improve the timetable capacity so as to tolerate disturbances in the train operation process.

\section{NETWORKED TRAIN OPERATION SIMULATION SYSTEM STRUCTURE}

To simplify the simulation process of train operation on a railway network, we assume that the orders from the Administration Dispatching Center could be sent to trains with no barriers and the train control process is ideal, meaning that there is no communication barriers for trains to operate. We employed the bi-level Petri net modeling method to do networked train operation simulation work. It is a model which includes the general network and the sub-network.

\subsection{Macroscopic network model of the system}

In previous studies, scholars usually built the Petri network simulation model for train operation with an automatic blocking system. A locked sub-section is considered as a place, and a train is described as a token. The place capacity is defined as 1 to assure that a locked sub-section can be occupied by a single train. The train occupies the sub-sections one by one. Accordingly, the token occupies the places one after another.

In this paper, we use the Petri net theory to construct the train simulation model with a moveable blocking system. To improve the universal properties of the simulation model, we consider the stations and the emergencies as places, and the train status, station status, and emergency attributes as tokens. The token propagation process is actually a process of information distribution.

A train decides its status by acquiring the information of the forward train and the information of the forward station. The process of trains operating in the railway network can be described as the information propagation process. The forward trains, forward stations, and the arrival-departure tracks are seen as three types of barriers.
The macroscopic model of a networked train operation system is shown in Figure 1.

Descriptions of detailed places, transitions, and colors are shown in Tables 1 and 2.

The color set descriptions of the networked train operation simulation system are as follows:

\section{Train color set}

closet TRAIN=product;

ID*ROUTE*TIME*POSITION*SPEED*STATUS

closet ID=string;//to define train number color.

closet ROUTE=string;//to define train operation path color.

closet TIME=int;//to define current train run-time color.

closet POSITION=float;//to define current train position color (that is, position in the path mileage.)

closet SPEED=float;// to define current train velocity color (km/h).

closet STATUS=bool;// to define train operation state color ("true" indicates that the train is running on a section between two stations, and "false" indicates that the train is waiting to depart at a station).

This color set includes the color properties of the trains. We use the color concept to describe the properties of the trains, such as train number, path, running time, speed, position, and status.

Table 1 - Description of total net Petri net model specific places and color sets

\begin{tabular}{|l|l|c||}
\hline \multicolumn{1}{|c|}{ Place name } & \multicolumn{1}{c|}{ Place description } & Color set \\
\hline \hline Train & Tracking train & TRAIN \\
\hline Train Front & Forward train & TRAIN \\
\hline Barrier & Barrier & BARRIER \\
\hline Station & Forward station & STATION \\
\hline $\begin{array}{l}\text { Arrival-departure } \\
\text { track }\end{array}$ & $\begin{array}{l}\text { Forward } \\
\text { arrival-departure } \\
\text { track }\end{array}$ & TRACK \\
\hline Emergency & Emergency & EMERGENCY \\
\hline $\begin{array}{l}\text { Inf1/Inf2/Inf3/ } \\
\text { Inf4 }\end{array}$ & $\begin{array}{l}\text { Train movement } \\
\text { information }\end{array}$ & TRAIN \\
\hline
\end{tabular}

Table 2 - The total Petri net model transfer descriptions

\begin{tabular}{||l|l||}
\hline \multicolumn{1}{|c|}{ Transfer name } & \multicolumn{1}{c|}{ Transfer description } \\
\hline \hline T_Tr & $\begin{array}{l}\text { Train and forward train constraint } \\
\text { handling }\end{array}$ \\
\hline T_St & $\begin{array}{l}\text { Train and forward station con- } \\
\text { straint handling }\end{array}$ \\
\hline T_Ar & $\begin{array}{l}\text { Train and forward arrival-departure } \\
\text { track constraint handling }\end{array}$ \\
\hline T_Em & $\begin{array}{l}\text { Train and current emergency } \\
\text { constraint handling }\end{array}$ \\
\hline $\begin{array}{l}\text { Trans1/Trans2/ } \\
\text { Trans3/Trans4 }\end{array}$ & $\begin{array}{l}\text { Processing information sent to the } \\
\text { train }\end{array}$ \\
\hline
\end{tabular}




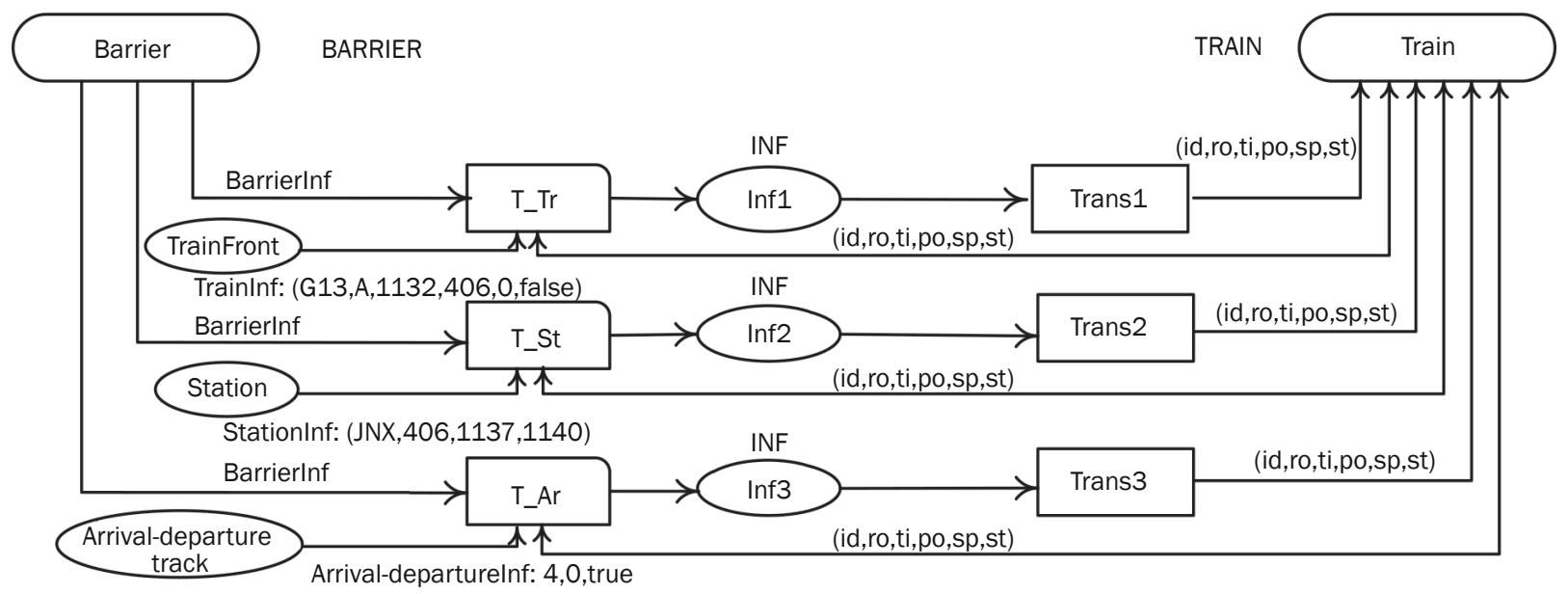

Figure 1 - Petri net model for networked train operation system

\section{Barrier color set}

closet BARRIER=with $\mathrm{Tr} / \mathrm{St} / \mathrm{Ar} / \mathrm{Em} ; / /$ to define the four kinds of barriers.

Barriers are used to denote objects that prevent trains from moving forward in the entire train operation process. In this paper, there are four kinds of barriers, a train in front of the concerned train, a station in front of the concerned train, a track in front of the concerned train, and an emergency occurred on the railway.

\section{Station color set}

closet STATION=product;

NAME*POSITIONS*ARRIVETIME*DEPARTURETIME

closet NAME=string;//to define train forward station name color

closet POSITIONS=int;// to define train forward station position color

closet ARRIVETIME=int;//to define train entering forward station fixed time color

closet DEPARTURETIME=int;// to define train entering forward station departure time color

The colors in this set are used to represent the properties of the stations. The properties include the name and position of a station, the arrival time at the concerned station, and the departure time from the concerned station.

\section{Arrival-departure track color set}

closet TRACE=product;

TOTALNUMBER *USEDNUMBER *ENTRANCE

closet TOTALNUMBER=int;// to define the total number of arrival-departure tracks.

closet USEDNUMBER=int;// to define the number of occupied arrival-departure tracks.

closet ENTRANCE=bool;//to define whether a train can enter a station. ("true" denotes yes, "false" denotes no)
The colors in this set denote the properties of arrival-departure tracks in a station. They are the total number of arrival-departure tracks, the number of occupied arrival-departure tracks, and the status of a station, which decides whether a train can enter the station.

\section{Emergency color set} closet EMERGENCY=product; EMERGENCY

closet TYPE=string;//define the type of emergency The color in this set is designed to define the type of emergency.

This integral net model describes the train operation process on a railway network, which reflects the restriction posed by barriers on trains. The restrictions include the speed limit caused by the forward train, the on-schedule requirement from the forward station, the number restriction of the arrival-departure track. The detailed restrictions are obtained by the barrier places and managed. They are then sent to the train to guide its proper operation.

In the model, the information processing between the train and the barrier is expressed in the form of "replacing transfer", which is not described in detail in the model, but is expressed in the form of the subnet. The following sub-sections describe the replacing transfer, which will be used to denote the information processing between trains and various barriers.

\subsection{Train tracking subnet model}

In the moving block system, the car following model mainly restricts the running speed of the track train, so as to ensure traffic safety. The train position information is transmitted to each train through the Administration Dispatching Center, and the train can obtain mobile authorization to continue to operate at the permitted speed. 


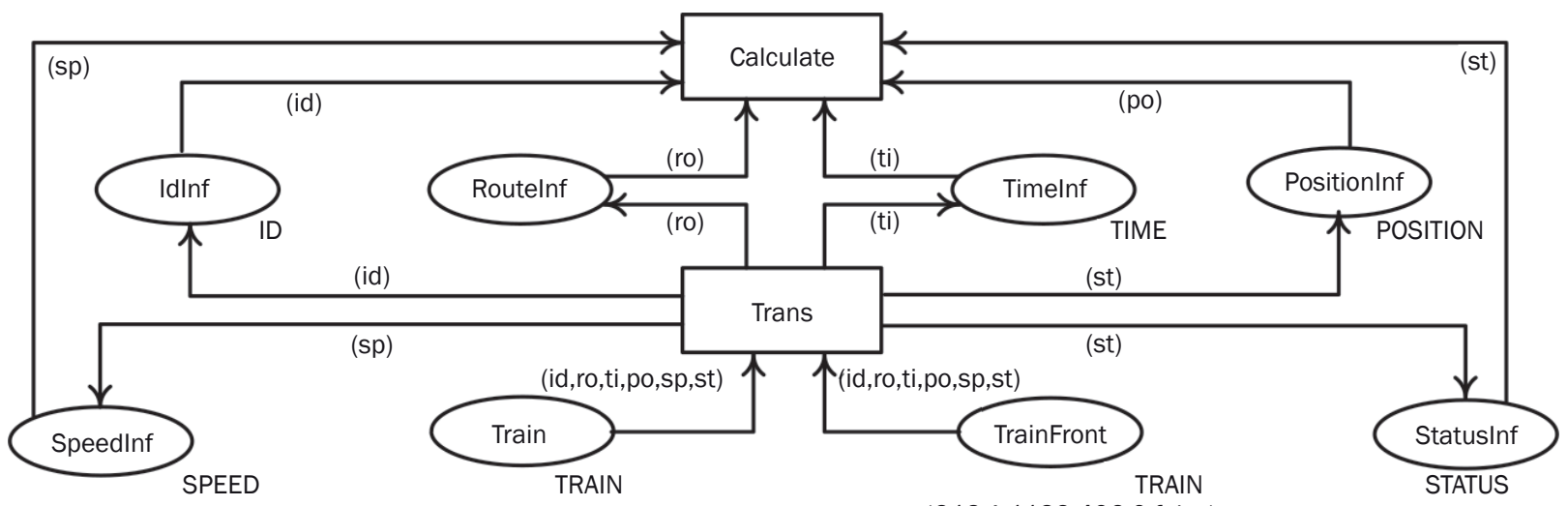

(G117,A,1132,377,207,true)

(G13,A,1132,406,0,false)

Figure 2 - Train tracking subnet model

The train tracking subnet model of a networked train operation system is shown in Figure 2.

Train tracking subnet model places and transfers are described in Tables 3 and 4.

Table 3 - Train tracking subnet model places and color sets descriptions

\begin{tabular}{||l|l|c||}
\hline \hline \multicolumn{1}{|c|}{ Place name } & \multicolumn{1}{c|}{ Place description } & Color set \\
\hline \hline Id Inf & Train number information & ID \\
\hline Route Inf & Train route information & ROUTE \\
\hline Time Inf & Current time information & TIME \\
\hline Position Inf & Train operation position & POSITION \\
\hline Speed Inf & Train operation speed & SPEED \\
\hline Status Inf & Train status & STATUS \\
\hline
\end{tabular}

Table 4 - Train tracking subnet model transfers description

\begin{tabular}{||l|l||}
\hline \hline Transfer name & \multicolumn{1}{|c|}{ Transfer description } \\
\hline \hline Calculate & Mobile authorization information process \\
\hline Trans & Train information transfer \\
\hline
\end{tabular}

This subnet model describes the relationship between forward trains and following trains. A key part of the model is to calculate the allowed maximum speed of the following trains based on the information of both forward and following trains. The information of following trains is updated according to the original information and the maximum speed in the simulation process. The cyclic process will last until the end of the simulation.

\subsection{Station subnet model}

The station subnet model is a sub-model of the networked train operation system model under the condition of emergency, which determines the inbound and outbound times of trains at stations.

The station subnet model is shown in Figure 3.
Table 5 - Places and colors set of the station subnet model

\begin{tabular}{||c|l|c|}
\hline Place name & Place description & Color set \\
\hline \hline Name Inf & $\begin{array}{l}\text { Forward station } \\
\text { name }\end{array}$ & NAME \\
\hline Positions Inf & $\begin{array}{l}\text { Forward station } \\
\text { positions }\end{array}$ & POSITIONS \\
\hline Arrive time Inf & $\begin{array}{l}\text { Station punctuality } \\
\text { arrival time }\end{array}$ & ARRIVETIME \\
\hline Departure Inf & $\begin{array}{l}\text { Station punctuality } \\
\text { departure time }\end{array}$ & DEPARTURETIME \\
\hline
\end{tabular}

Table 6 - Transfers of station subnet model

\begin{tabular}{|l|l|}
\hline \hline Transfer name & \multicolumn{1}{|c|}{ Transfer description } \\
\hline \hline Calculate & Mobile authorization information process \\
\hline Station trans & Station information transfer \\
\hline
\end{tabular}

The places and transfers of the station subnet model are shown in Tables 5 and 6.

This station subnet model describes the relationship between the trains and the forward stations. The allowed maximum speed of the train is calculated based on the status information and schedule requirement. The train status is updated according to the train speed and the original information of it.

\subsection{Station arrival-departure track subnet model}

The number of tracks at the stations must be considered when simulating train operation on a railway network because a station is required to accommodate trains from all directions. Therefore, we designed a station arrival-departure track subnet model to describe the restriction and take the track number restriction into consideration. The station arrival-departure track subnet model is shown in Figure 4.

The transfers and color sets of the station arrival-departure track subnet model are listed in Table 7. The related places are shown in Table 8. 


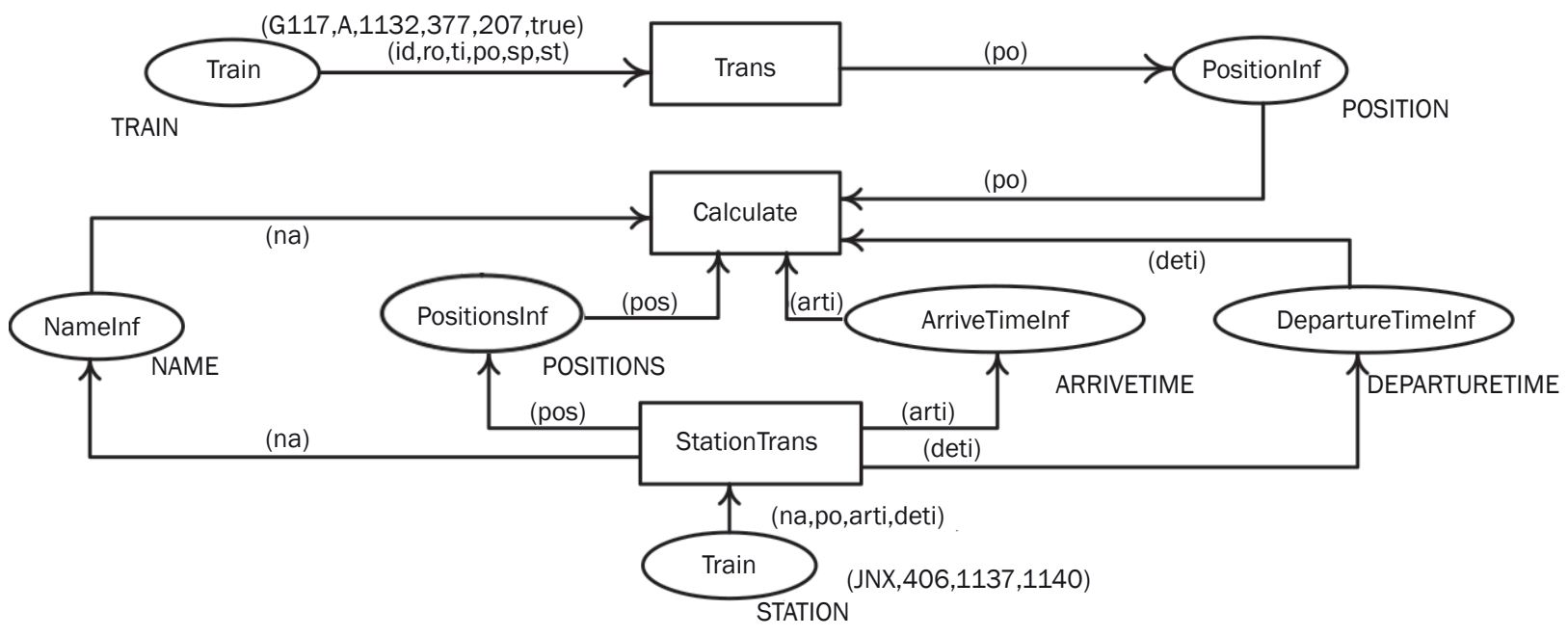

Figure 3 - Station subnet model description

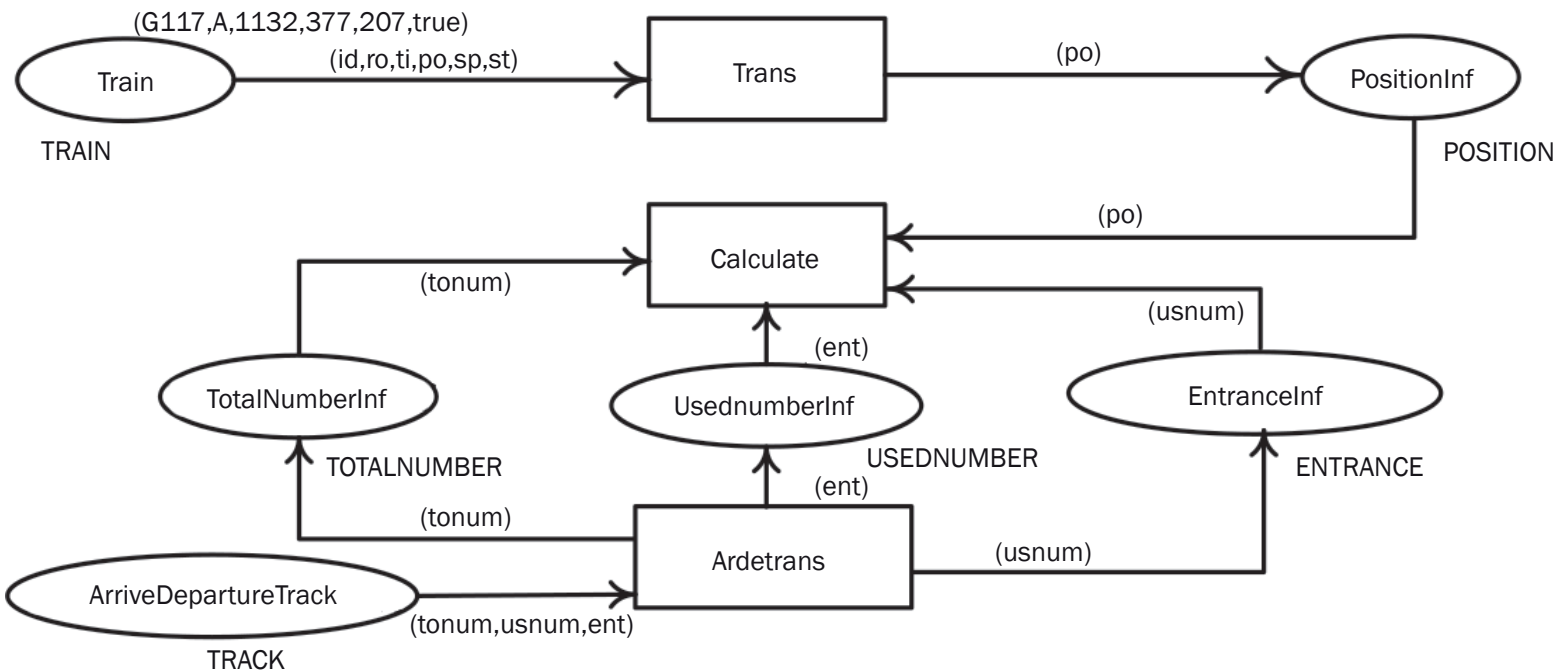

Figure 4 - Station arrival-departure track subnet model description

Table 7 - Places and descriptions of the station arrivaldeparture track subnet model

\begin{tabular}{||c|l|c||}
\hline Place name & \multicolumn{1}{|c||}{ Place description } & Color set \\
\hline \hline Total number Inf & $\begin{array}{l}\text { Arrival-departure } \\
\text { track total number }\end{array}$ & $\begin{array}{c}\text { TOTALNUM- } \\
\text { BER }\end{array}$ \\
\hline Used number Inf & $\begin{array}{l}\text { Arrival-departure } \\
\text { track used number }\end{array}$ & USEDNUMBER \\
\hline Entrance Inf & Station entrance & ENTRANCE \\
\hline
\end{tabular}

Table 8 - Transfers of station arrival-departure track subnet model

\begin{tabular}{||l|l||}
\hline Transfer name & \multicolumn{1}{|c|}{ Transfer description } \\
\hline \hline Calculate & Mobile authorization information process \\
\hline Ardetrans & $\begin{array}{l}\text { Station arrival-departure track } \\
\text { information process }\end{array}$ \\
\hline
\end{tabular}

The following is the supplement description of the color set of the arrival-departure track subnet model. closet ENTRANCE=product;

\section{COMMAND}

closet $\mathrm{COMMAND=bool;//} \mathrm{The} \mathrm{bool} \mathrm{variable} \mathrm{indicates}$ whether the train can enter the station (true denotes that it can enter the station, false denotes that it cannot enter the station).

The subnet model describes whether the station can accommodate a train, which is decided by the fact whether all of the arrival-departure tracks are occupied.

\section{COMPUTING CASE AND RESULT ANALYSIS}

In this section, we designed a computing case in an effort to prove the feasibility of the model. The data was from a part of the Chinese railway network. We drew a sketch map of the selected part of the railway 
Meng X, Jia L, Xiang W. A Petri Net Model of Train Operation Simulation for Harmonizing Train Timetables of Neighbor Dispatching Sections

Table 9 - Station names and corresponding abbreviated forms

\begin{tabular}{||l|c|l|c|}
\hline \multicolumn{1}{|c|}{ Station name } & Abbreviated Forms & \multicolumn{1}{c|}{ Station name } & Abbreviated Forms \\
\hline \hline Xuzhoudong & XZD & Suzhoubei & SZB \\
\hline Bengbunan & BBN & Shanghai & SH \\
\hline Huainan & HN & Changlinhe & CH \\
\hline Shuijiahu & SJH & Chaohu & WH \\
\hline Hefei & HF & Wuhu & TL \\
\hline Feidong & FD & Tongling & GJ \\
\hline Quanjiao & QJ & Gejiang & XC \\
\hline Nanjingnan & NJN & Xuancheng & HZ \\
\hline Chuzhou & CZ & Guangde & YX \\
\hline Zhenjiangnan & HJN & Huzhou & LS \\
\hline Changzhoubei & YZB & Lishui & SZD \\
\hline Wuxidong & WXD & Suzhoudong & \\
\hline Liyang & LY & & \\
\hline
\end{tabular}

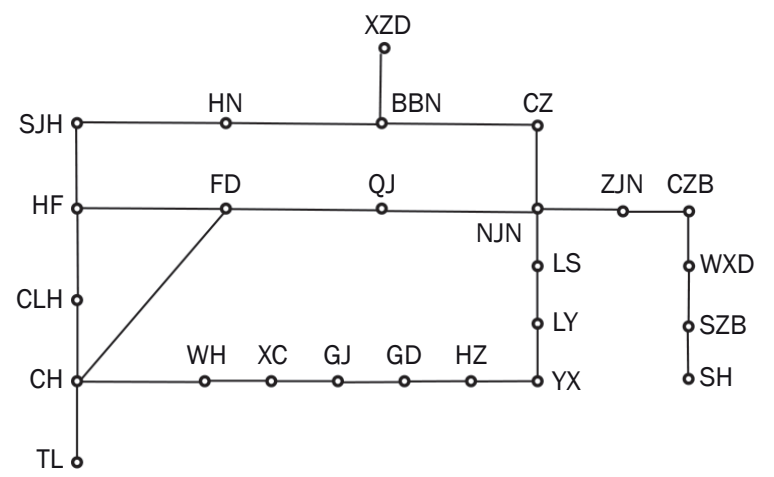

Figure 5 - Schematic diagram of some high speed railway lines in China

network, which is shown in Figure 5. In the figure, we used the abbreviated form of the station names. Here is the list of the stations names and their abbreviated forms, as shown in Table 9.

We took the Nanjingnan station as the core node, and the trains that arrive at Nanjingnan station from 10 a.m. to 11 a.m. as the research objects.

There are 4 related train operation paths. The first one (Path 1) is from Suzhoudong to Wuxidong. Its original train operation diagram is shown in Figure 6, and the detailed timetable data is shown in Tables 10 and 11. The second (Path 2) is from Suzhoudong to Yixing. Its original train operation diagram is shown in Figure 7 , and the detailed timetable data is shown in Table 12. The third (Path 3) one is from Yixing to Nanjingnan. The original train operation diagram is shown in Figure 8, and the detailed data is listed in Table 13. The last one (Path 4) is from Hefei to Yixing. The original train operation diagram is shown in Figure 9, and the detailed data is listed in Tables 14 and 15.

We instantiated the simulation model based on the data above, programming with MATLAB R2009. The goal was to harmonize the train timetables of neighbor dispatching sections, assuming Nanjingnan as the terminal station. The optimized timetable of Path 1 is shown in Tables 16 and 17 . The relative train diagram is shown in Figure 10. The optimized timetable of Path 2 is shown in Table 18. The relative train diagram is shown in Figure 11. The optimized timetable of Path 3 is shown in Table 19. The relative train diagram is shown in Figure 12. The optimized timetable of Path 4 is shown in Tables 20 and 21 . The relative train diagram is shown in Figure 13.

Set $P=20 \%$, where $P$ is the probability that an emergency may happen. Set the maximum speed $V_{\max }=330$ $\mathrm{km} / \mathrm{h}$, minimum interval between two neighbored trains $t_{\text {min }}=3$. In addition, we took it for granted that if a forward train arrives at the station, the speed of the following train is not affected in this section.

From Figure 10 we can see that the inbound and outbound times of 2 trains which go through the Nanjing station in the up-going direction were adjusted to cope with the $20 \%$ emergency probability. From Figure 11 we can see that one of the trains changed its inbound and outbound times at the Nanjingnan station. Figure 13 shows that 2 trains changed their inbound and outbound times at the Nanjingnan station. It indicates that the station cannot allow the entrance of all the planned trains if the emergency probability is $20 \%$. The number of arrival-departure tracks should be enlarged. Similarly, all of the trains changed their inbound and outbound times at the Bengbunan station in this case. It implies that the capacity of the Bengbunan station is too small to deal with the emergency. More arrival-departure tracks should be added at the station to cope with the emergency. We can get similar analysis results on other stations and propose some construction advice based on the analysis results. 


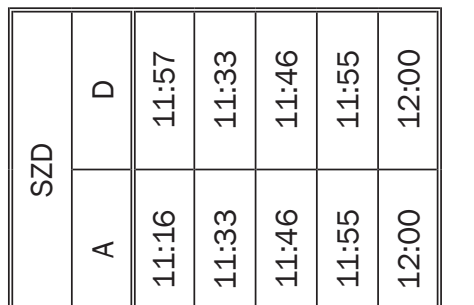

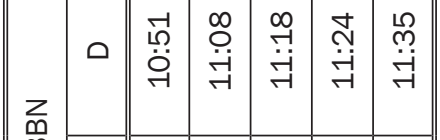

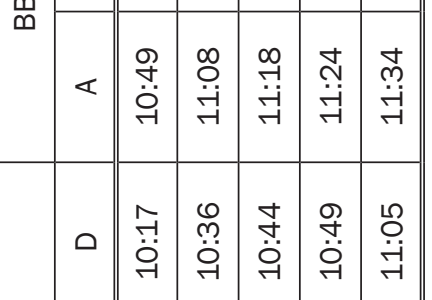

N

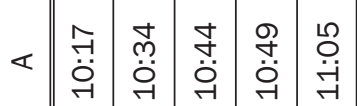

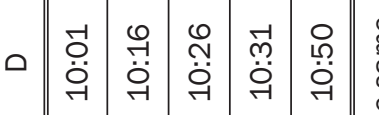

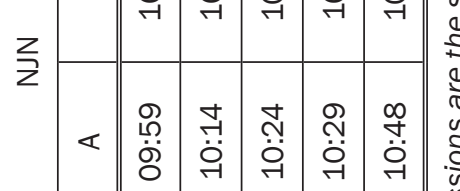

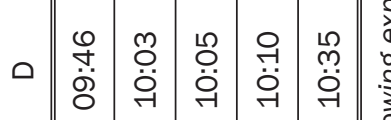

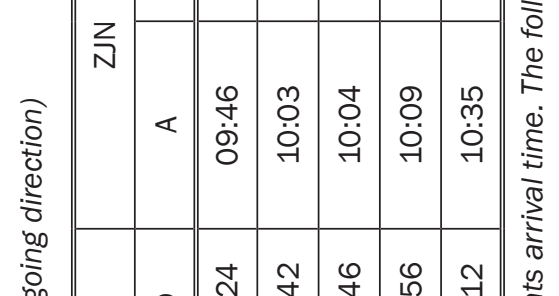

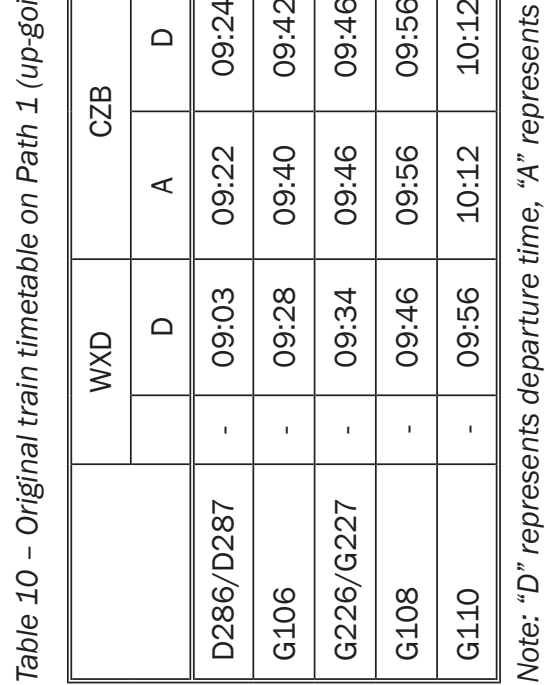

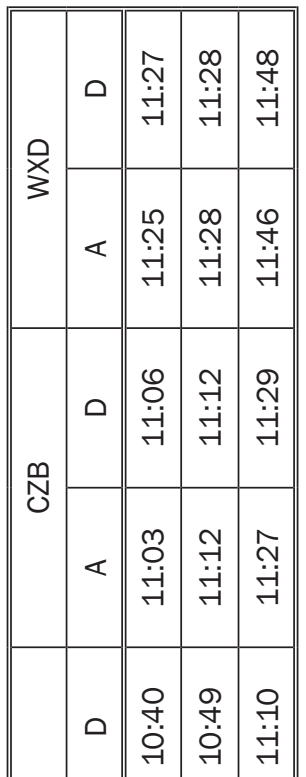

六

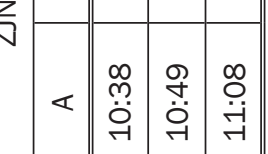

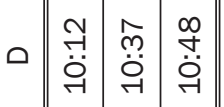

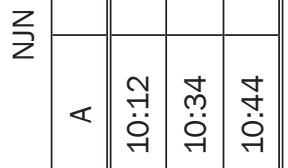

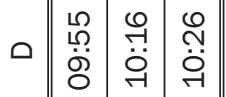

N

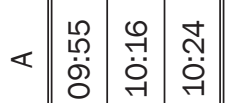

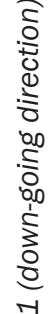

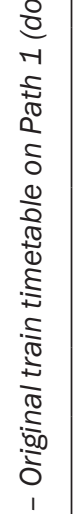

$\frac{\sqrt{0}}{\frac{9}{4}}$

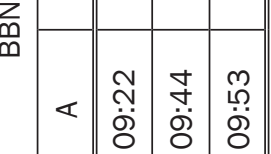

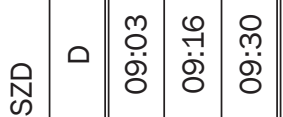

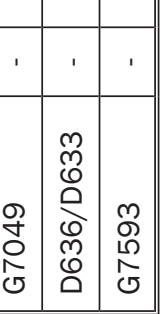

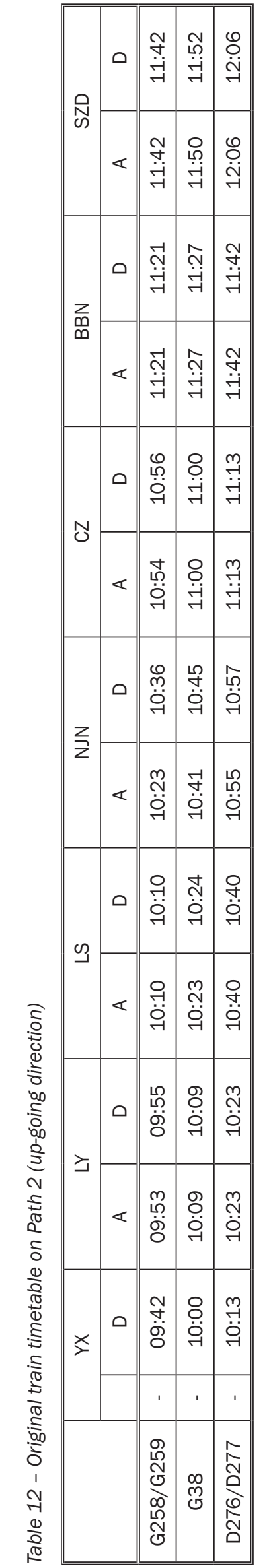

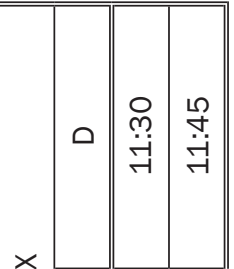

$\stackrel{×}{x}$

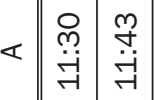

•

$\succeq$

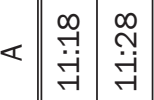

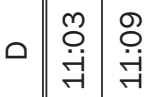

( )
<

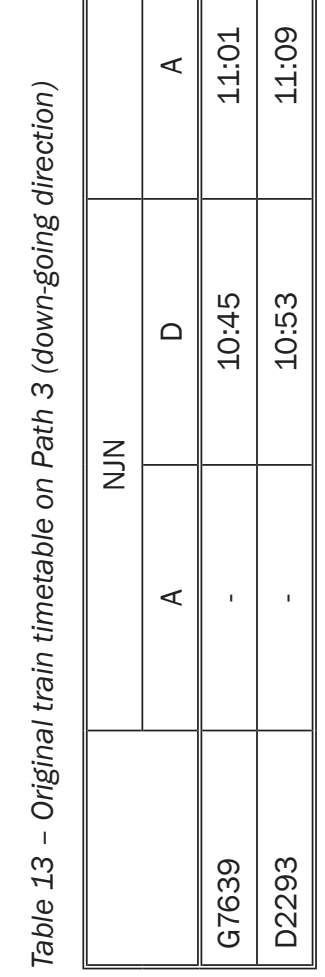



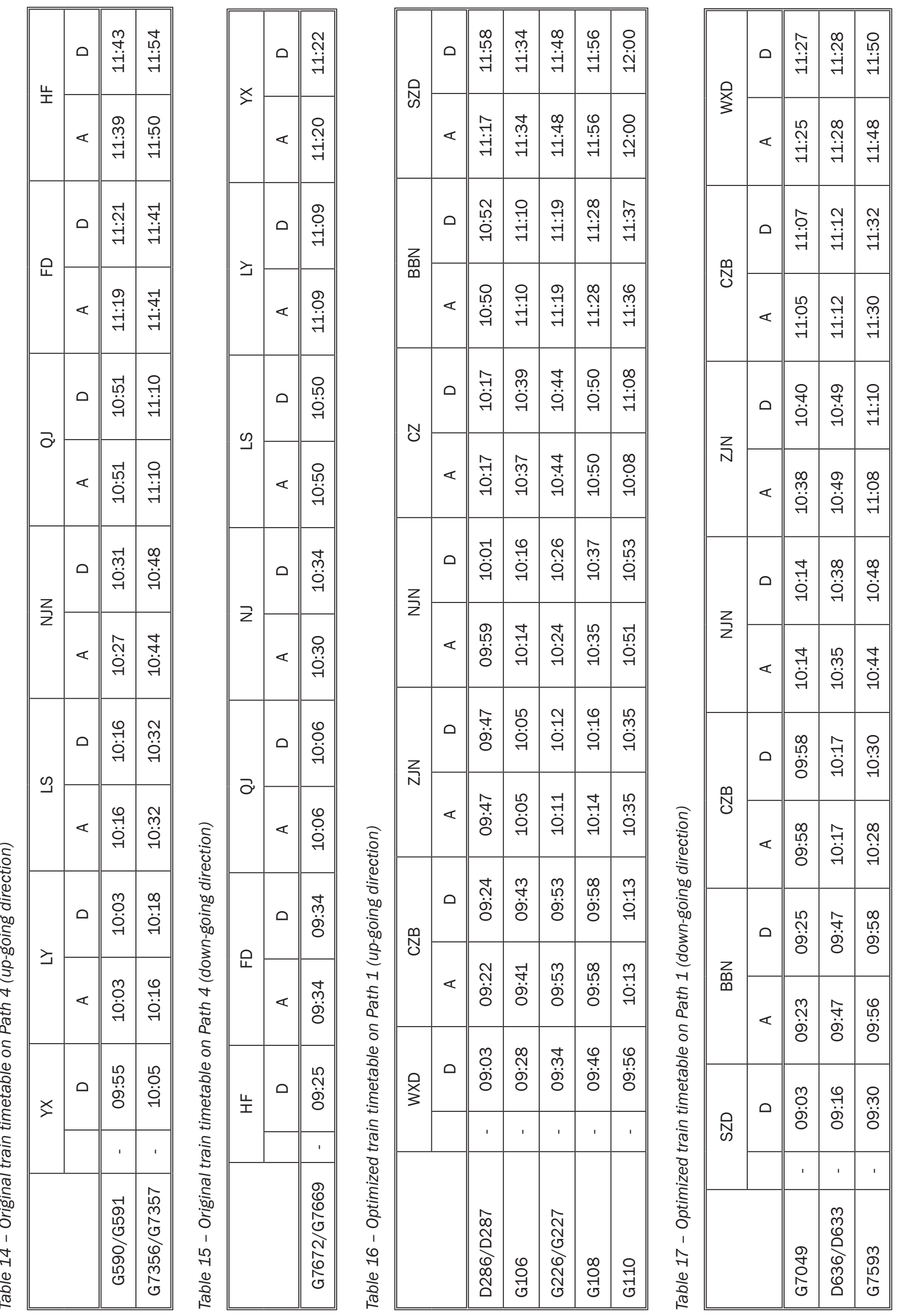


\begin{tabular}{|c|c|c|c|c|}
\hline \multirow{2}{*}{ Nิ } & 口 & $\begin{array}{l}\text { ৪ } \\
\text { ஸे }\end{array}$ & $\begin{array}{l}\text { ț } \\
\text { ஸे }\end{array}$ & $\begin{array}{l}\text { ㄱำ } \\
\text { }\end{array}$ \\
\hline & $\varangle$ & $\begin{array}{l}\text { ○ } \\
\text { ஸें }\end{array}$ & $\begin{array}{l}\text { Oे } \\
\text { ஸे }\end{array}$ & 궙 \\
\hline \multirow{2}{*}{ ב⿳亠丷⿵冂⿱丷口心 } & 口 & $\begin{array}{l}\stackrel{-}{m} \\
\stackrel{\leftrightarrow}{-}\end{array}$ & $\begin{array}{l}\stackrel{\text { m}}{\mathrm{G}} \\
\text { t. }\end{array}$ & $\begin{array}{l}0 \\
\stackrel{+}{-} \\
\stackrel{-}{-}\end{array}$ \\
\hline & $\varangle$ & $\stackrel{\stackrel{\leftrightarrow}{\oplus}}{\stackrel{-}{\rightarrow}}$ & 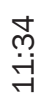 & $\begin{array}{l}\stackrel{0}{+} \\
\stackrel{-}{ت}\end{array}$ \\
\hline \multirow{2}{*}{$\mathcal{N}$} & 口 & $\begin{array}{l}\hat{L} \\
\stackrel{\rho}{0}\end{array}$ & $\begin{array}{l}\text { Oֶ } \\
\text { ت̇ }\end{array}$ & \\
\hline & $\varangle$ & $\begin{array}{l}\text { 吊 } \\
\text { Ọ̊ }\end{array}$ & $\begin{array}{l}\text { Oֶ } \\
\text { تै }\end{array}$ & \\
\hline \multirow{2}{*}{ z } & 口 & $\begin{array}{l}0 \\
\text { } \\
\ddot{\sigma}\end{array}$ & 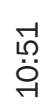 & \\
\hline & $\varangle$ & 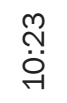 & $\begin{array}{l}\hat{f} \\
\stackrel{\leftrightarrow}{\circ}\end{array}$ & مُ \\
\hline \multirow{2}{*}{ 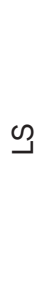 } & 口 & $\begin{array}{l}\text { नै } \\
\stackrel{\leftrightarrow}{\oplus}\end{array}$ & $\begin{array}{l}\stackrel{+}{0} \\
\stackrel{\leftrightarrow}{0}\end{array}$ & \\
\hline & $\varangle$ & 굼 & $\begin{array}{l}\stackrel{n}{0} \\
\stackrel{\sim}{*}\end{array}$ & \\
\hline \multirow{2}{*}{$\succeq$} & 口 & $\begin{array}{l}\text { 员 } \\
\text { Oें }\end{array}$ & $\begin{array}{l}\stackrel{g}{0} \\
\text { ळे }\end{array}$ & \\
\hline & $\ll$ & $\begin{array}{l}\stackrel{0}{\leftrightarrow n} \\
\text { Oे }\end{array}$ & $\begin{array}{l}\text { go } \\
\text { ه़े }\end{array}$ & \\
\hline \multirow[t]{3}{*}{ 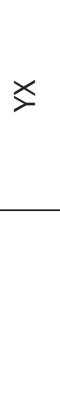 } & 0 & $\begin{array}{l}\stackrel{N}{+} \\
\stackrel{8}{\circ}\end{array}$ & $\begin{array}{l}8 \\
\text { ओं }\end{array}$ & 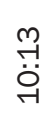 \\
\hline & & ' & & \\
\hline & & 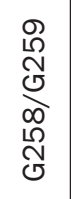 & 必 & 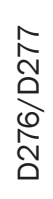 \\
\hline
\end{tabular}
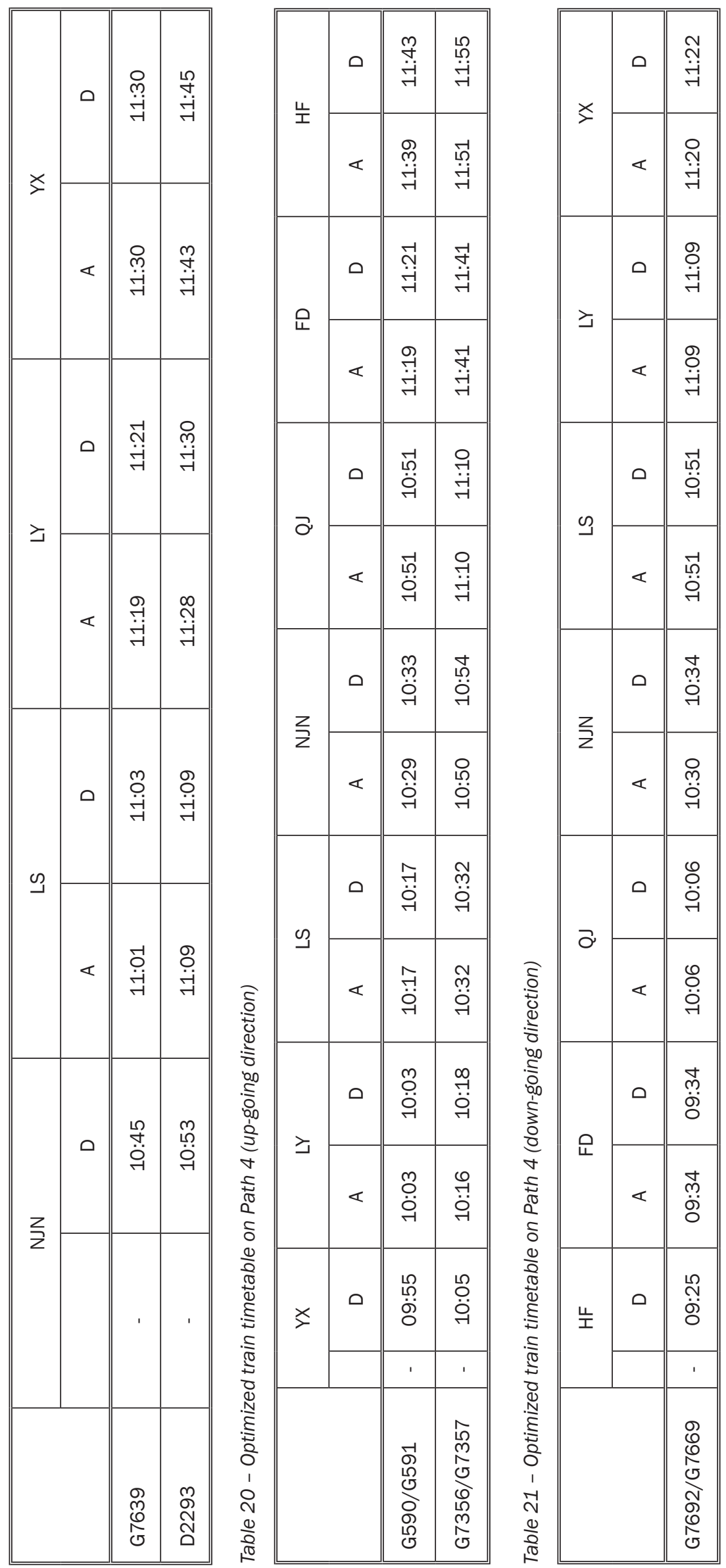


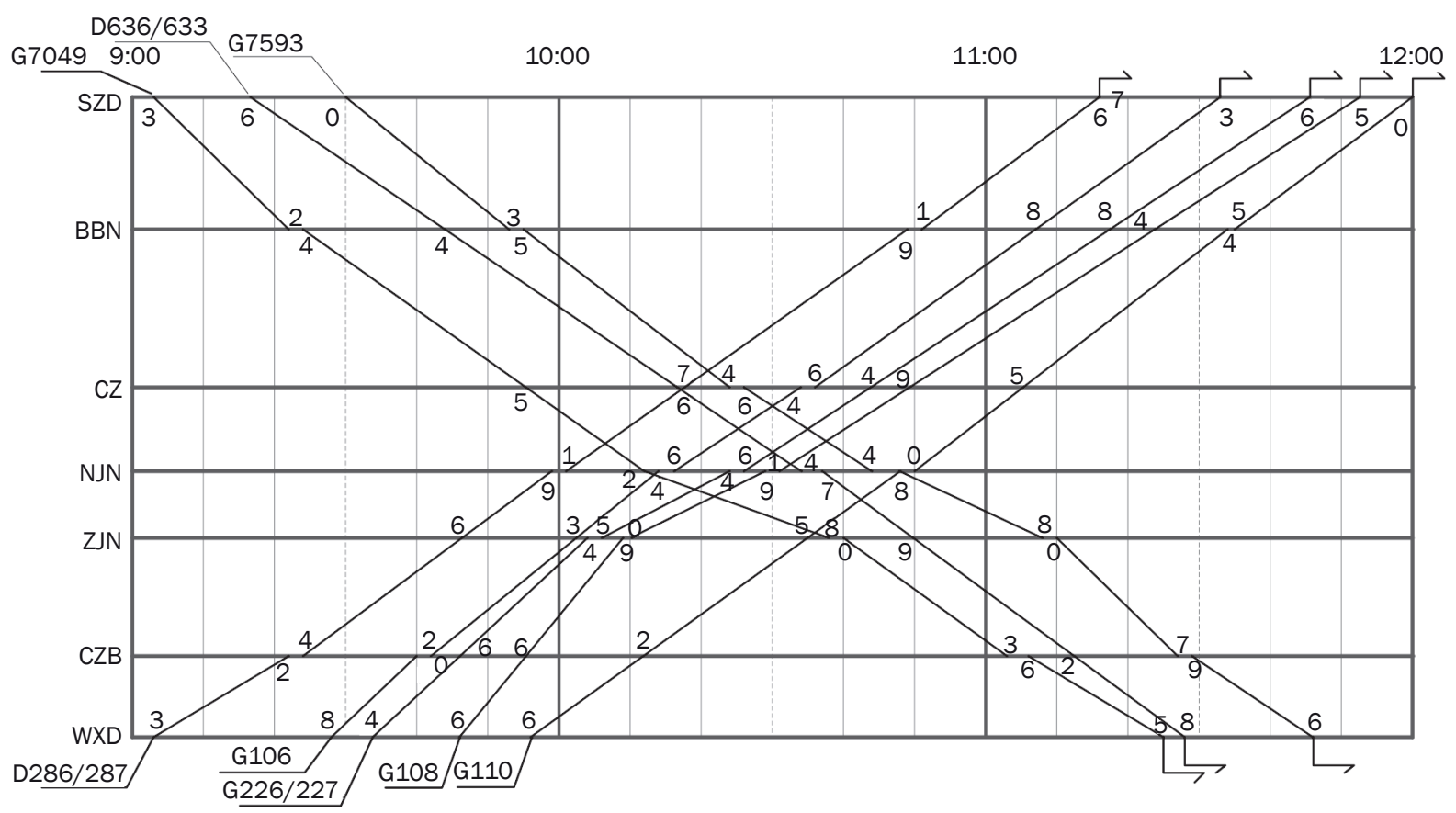

Figure 6 - Original train operation diagram on Path 1

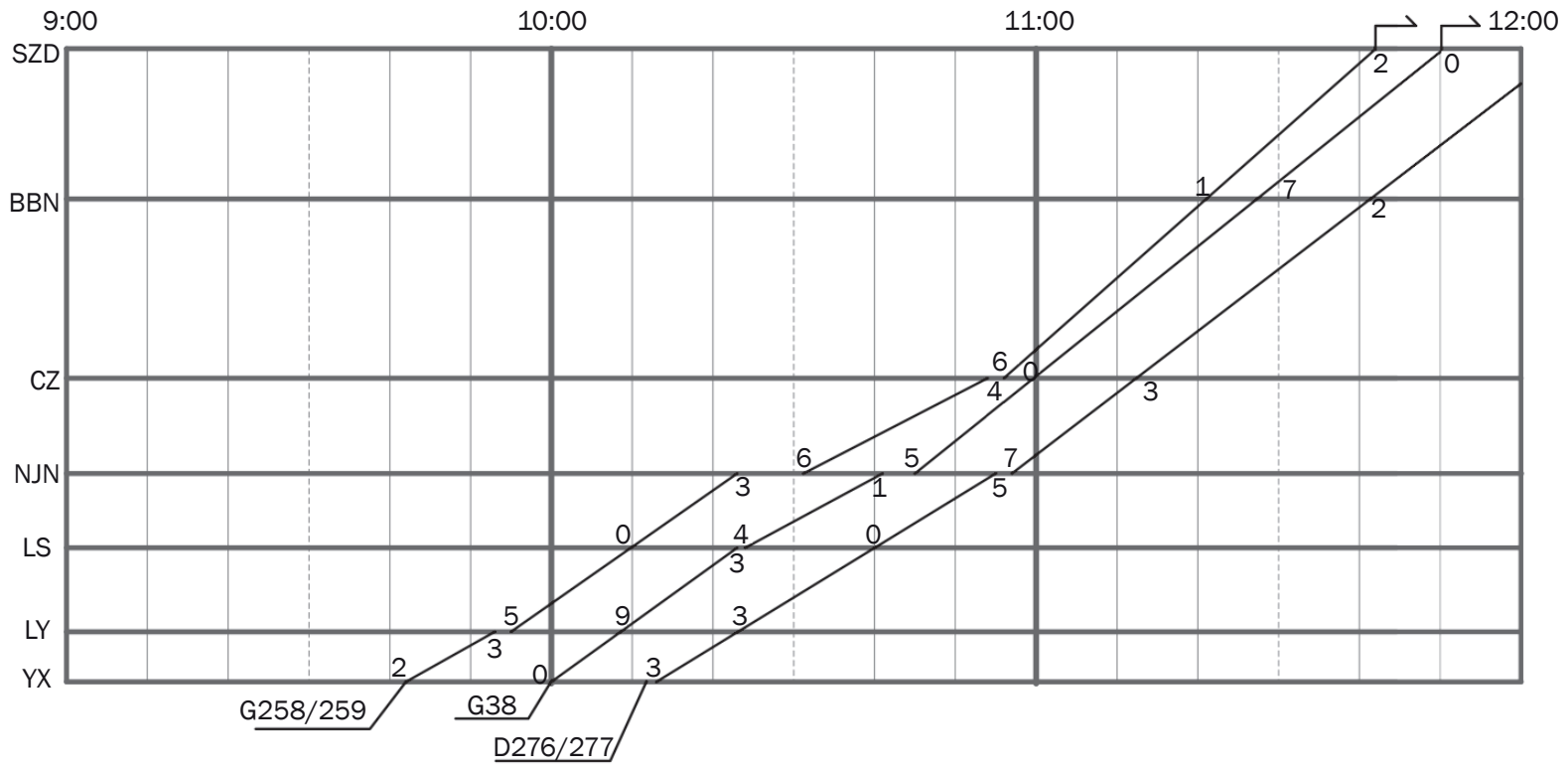

Figure 7 - Original train operation diagram on Path 2

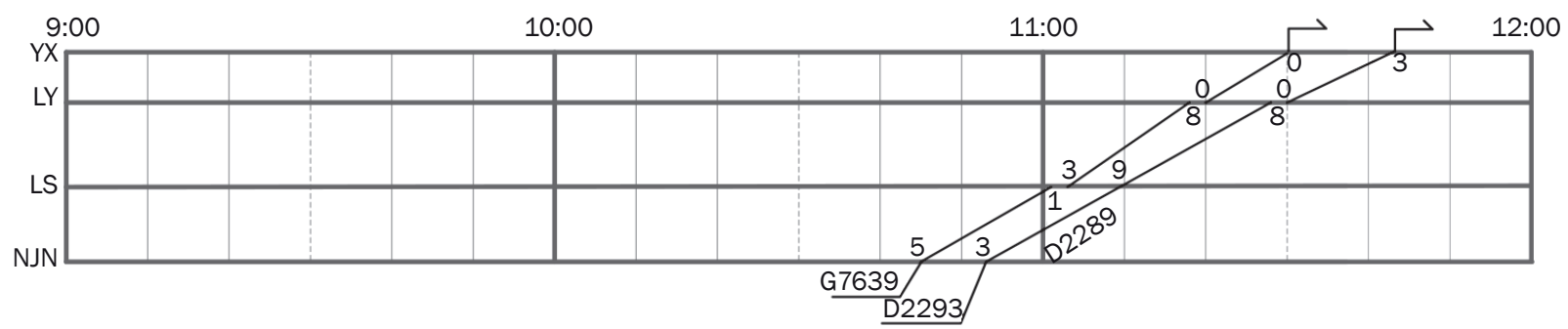

Figure 8 - Original train operation diagram on Path 3 

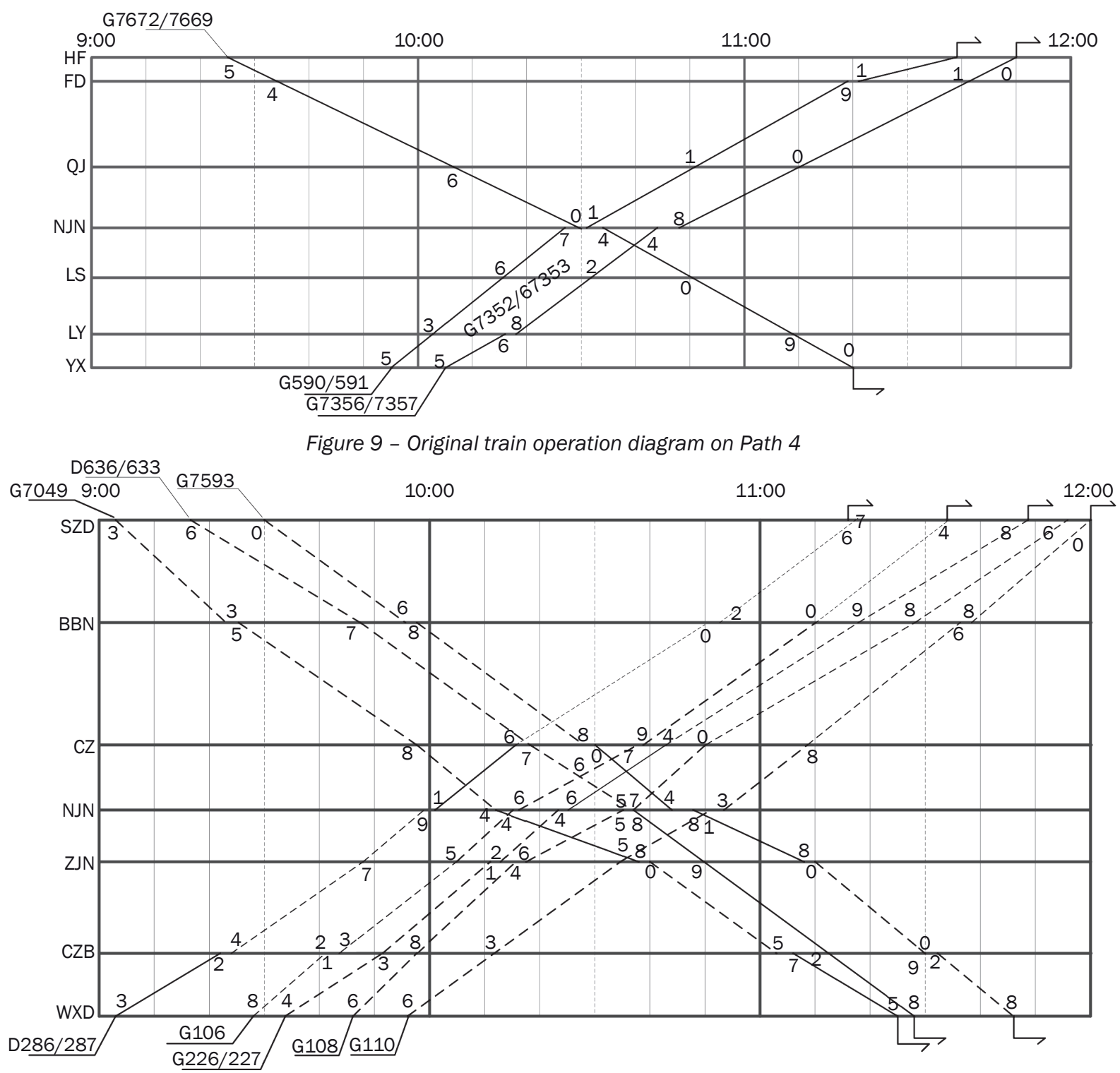

Figure 10 - Optimized train operation diagram on Path 1

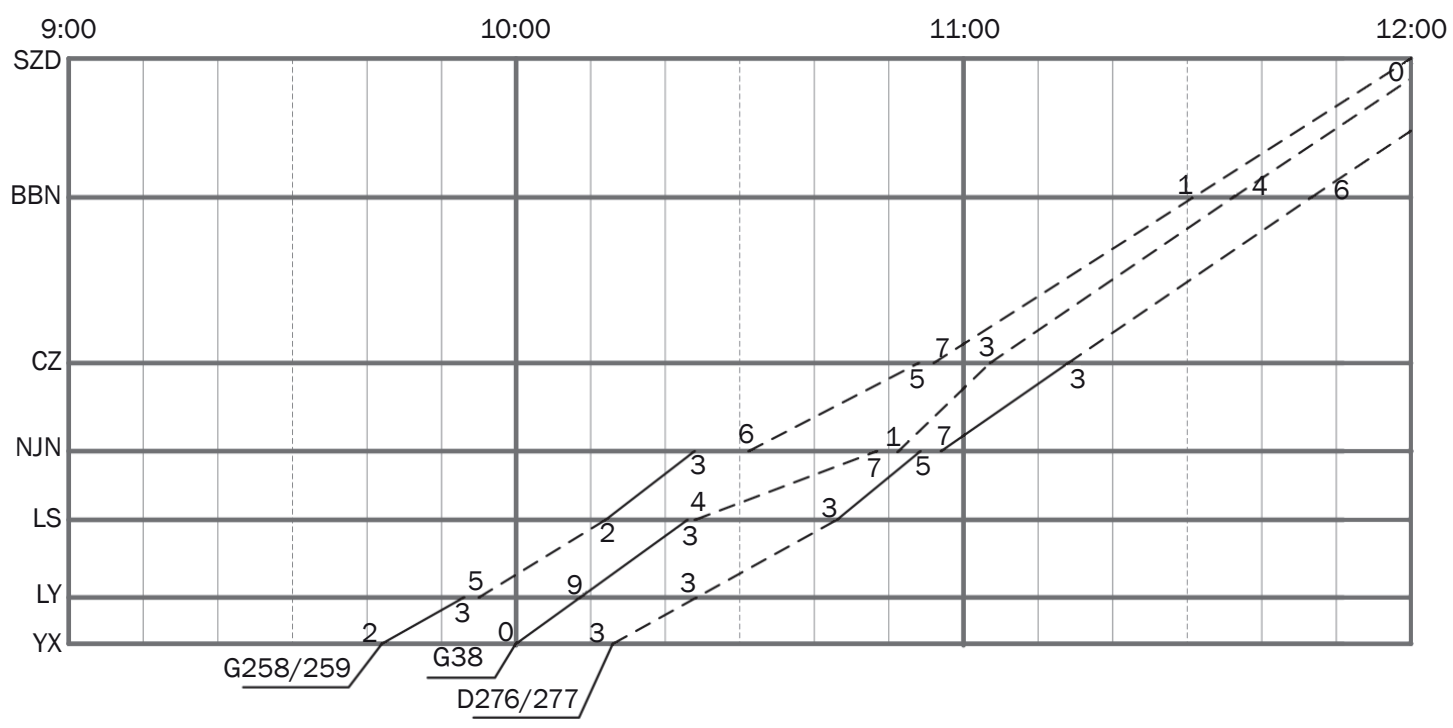

Figure 11 - Optimized train operation diagram on Path 2 


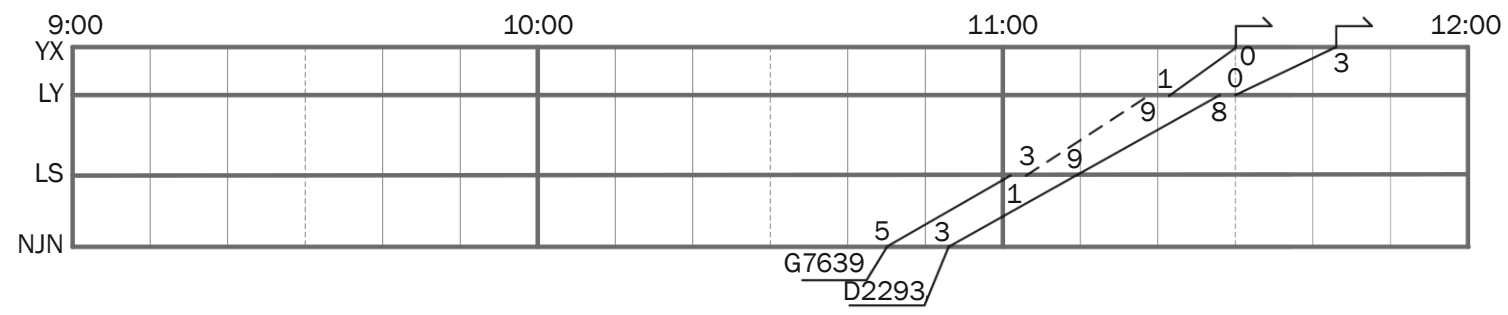

Figure 12 - Optimized train operation diagram on Path 3

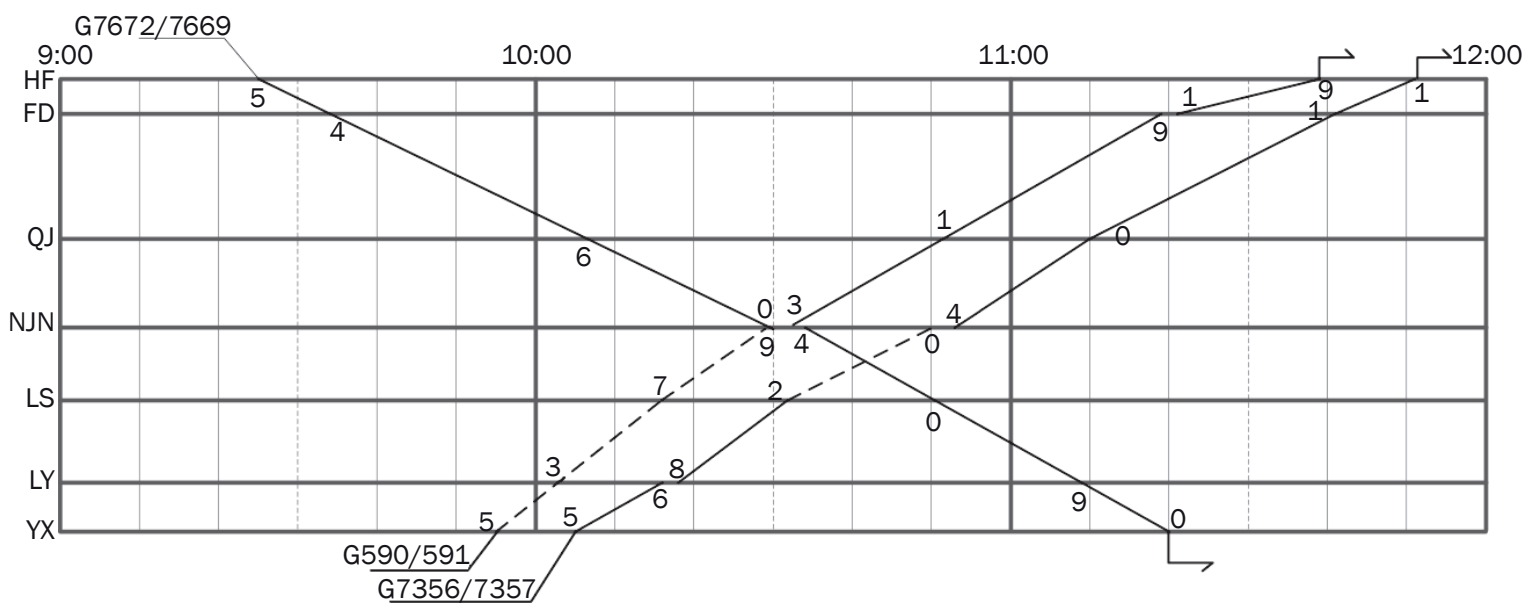

\section{CONCLUSION}

This paper constructed a simulation model for trains on a railway network, using the colored Petri network theory. We denoted trains as places. Then the status of the tracking trains and the forward trains, the status of the stations, the status of the arrival-departure tracks, and the status of the emergencies were taken as tokens. The statuses of every minute were connected, and the simulation model was constructed.

A general-subnet network was constructed, taking the tracking constraints, the on-schedule constraint, the arrival-departure track constraint, and the emergency constraint as substitute transitions, which made the structure of the network more distinct and the description of the model more concise.

The data of the computing case was from the Shanghai Railway Bureau. The data referred to the period from 9 to 12 o'clock. The studied objects were trains passing the Nanjing South station. The computing results showed that the model in this paper could simulate train operation movements accurately. The approach can generate a large number of timetables of neighbor railway sections for us to select. Although we cannot firmly state that we can obtain the optimal solution, it is certain that we can get a feasible and high quality one. Such solution could help evaluate and provide supporting information to improve timetable stability. The optimized timetable could tolerate tiny disturbances through re-distributing the redundant operation time on the railway section.

\section{ACKNOWLEDGMENTS}

This work is supported by the Foundation of a Hundred Young Talents Training Program of Lanzhou Jiaotong University (Grant No.1520220210), State Key Laboratory of Rail Traffic Control and Safety (Contract No. RCS2018K012), Beijing Jiaotong University, the National Key Research \& Development Project of China (Grant 2016YFB1200100), National Natural Science Foundation of China (Grant Nos. 71861022, 61563028) and the Natural Science Foundation of Gansu Province, China (Grant: 1610RJZA047).

孟学雷 ${ }^{1,2}$ (博士), 贾利民 ${ }^{2}$ (博士), 向万里 ${ }^{1}$ (博士)

1 兰州交通大学交通运输学院, 中国甘肃省兰州市安宁区 安宁西路88号405信箱, 邮编：730070

2 北京交通大学轨道交通控制与安全国家重点实验室, 中国北京市海淀区上园村3号北京交通大学, 邮编: 100044

通讯作者: 孟学雷, 邮箱: mxl@mail.Izjtu.cn

相邻调度区段列车运行图协同优化的PETRI网列车运 行仿真模型

摘要

列车运行图是指挥列车运行的关键文件, 通过调整列 车运行控制列车正常的运行秩序。列车运行图的稳定性与 列车正点率紧密相关。高质量的运行图可以吸收列车运行 过程中因受到干扰而造成的晚点, 并保证列车的正点率。 本文通过仿真的方法提升相邻区段的列车运行图的稳定 性, 保证列车的正点率。首先, 利用Petri网在铁路路网层 面构建了列车运行的宏观模型。然后, 设计了列车追踪运 行子网络模型、车站子网络模型以及到发线子网络模型。 
最后，设计了一个仿真实例，基于提出的仿真模型，对列 车的运行过程进行了仿真，仿真结果验证了模型的可行性 与有效性。本论文所设计的方法可为列车运行图编制者提 供有价值的决策支持。

\section{关键词}

列车运行; Petri网; 仿真; 相邻调度区段

\section{REFERENCES}

[1] Keijia K, Naohikob H, Shigerub M. Simulation analysis of train operation to recover knock-on delay under high-frequency intervals. Case Studies on Transport Policy. 2015;3(1): 92-98.

[2] Flynn D, Hemida H, Soper D, Baker C. Detached-eddy simulation of the slipstream of an operational freight train. Journal of Wind Engineering and Industrial Aerodynamics. 2014;132: 1-12.

[3] Mihailovs F, Sansyzbajeva Z, Mezitis M. Simulation of the interaction of railway station and harbor. Procedia Computer Science. 2017;104: 222-226.

[4] Warg J, Bohlin M. The use of railway simulation as an input to economic assessment of timetables. Journal of Rail Transport Planning and Management. 2016;6(3): 255-270.

[5] Debois S, Hildebrandt T, Sandberg L. Experience report: constraint-based modelling and simulation of railway emergency response plans. Procedia Computer Science. 2016;83: 1295-1300.

[6] Nagel K, Schreckenberg M. A cellular automaton model for freeway traffic. Journal of Physics I France. 1992;2: 2221-2229.

[7] Spyropoulou I. Modelling a signal controlled traffic stream using cellular automata. Transportation Research Part C: Emerging Technologies. 2007;15(3): 175-190.

[8] Kheldoun A, Barkaoui K, loualalen M. Formal verification of complex business processes based on high-level Petri nets. Information Sciences. 2017;385-386: 39-54.

[9] Wang P, Fang W, Guo B. A colored Petri nets based workload evaluation model and its validation through Multi-Attribute Task Battery-II. Applied Ergonomics. 2017;60: 260-274.

[10] Pachpor PS, Shrivastava RL, Seth D, Pokharel S. Application of Petri nets towards improved utilization of machines in job shop manufacturing environments. Journal of Manufacturing Technology Management. 2017;28(2): JMTM-05-2016-0064.

[11] Milinković S, Marković M, Vesković S, Ivić M, Pavlović N. A fuzzy Petri net model to estimate train delays. Simulation Modelling Practice and Theory. 2013;33: 144-157.

[12] Ahmad F, Khan SA. Specification and verification of safety properties along a crossing region in a railway network control. Applied Mathematical Modelling. 2013;37(7): 5162-5170.

[13] Boudi Z, Miloudi E, Koursi E, Collart-Dutilleul S. From place/transition Petri nets to B abstract machines for safety critical systems. IFAC-PapersOnLine. 2015;48(21): 332-338.

[14] Khan SA, Zafar NA, Ahmad F, Islam S. Extending Petri net to reduce control strategies of railway interlocking system. Applied Mathematical Modelling. 2014;38(2): 413-424.
[15] Ricci S. The use of Petri nets models in railway traffic applications. IFAC Proceedings Volumes. 2009;42(5): 151-156.

[16] Basile F, Cabasino MP, Seatzu C. Diagnosability Analysis of Labeled Time Petri Net Systems. IEEE Transactions on Automatic Control. 2017;62(3): 1384-1396.

[17] Kaakai F, Hayat S, Moudni AE. A hybrid Petri netsbased simulation model for evaluating the design of railway transit stations. Simulation Modelling Practice and Theory. 2007;15(8): 935-969.

[18] Quiroga LM, Wegele S, Schnieder E. Benefit of railway infrastructure diagnosis systems on its availability. IFAC Proceedings Volumes. 2009;42(5): 146-150.

[19] Marrone S, Rodríguez RJ, Nardone R, Flammini F, Vittorinic V. On synergies of cyber and physical security modelling in vulnerability assessment of railway systems. Computers and Electrical Engineering. 2015;47: 275-285.

[20] Wang P, Ma L, Goverde RMP, Wang Q. Rescheduling trains using Petri nets and heuristic search. IEEE Transactions on Intelligent Transportation Systems. 2016;17(3): 726-735.

[21] Durmuş MS, Yildirim U, Söylemez MT. Interlocking system design for ERTMS/ETCS: an approach with Batches Petri Nets. IFAC Proceedings Volumes. 2012;45(29): 110-115.

[22] Goverde RMP. Railway timetable stability analysis using max-plus system theory. Transportation Research Part B: Methodology. 2007;41(2): 179-201.

[23] Delorme X, Gandibleux X, Rodriguez, J. Stability evaluation of a railway timetable at station level. European Journal of Operational Research. 2009;195(3): 780-790.

[24] Engelhardt-Funke O, Kolonko M. Analysing stability and investments in railway networks using advanced evolutionary algorithm. International Transactions in Operational Research. 2004;11(4): 381-394.

[25] Niu H, Zhou X, Gao R. Train scheduling for minimizing passenger waiting time with time-dependent demand and skip-stop patterns: Nonlinear integer programming models with linear constraints. Transportation Research Part B: Methodology. 2015;76: 117-135.

[26] Hansen IA. Station capacity and stability of train operations. Advances in Transport, Computers in Railways VII. 2000; 7: 809-816.

[27] Cicerone S, D'Angelo G, Stefano GD, Frigioni D, Navarra A. Recoverable robust timetabling for single delay: complexity and polynomial algorithms for special cases. Journal of Combination Optimization. 2009;18(3): 229-257.

[28] Liebchen C, Stille S. Delay resistant timetabling. Public Transport. 2009;1(1): 55-72.

[29] D'Angelo G, Stefano GD, Navarra A, Pinotti CM. Recoverable robust timetables: An algorithmic approach on trees. IEEE Transactions Computers. 2011;60(3): 433-446.

[30] Cicerone S, Stefano GD, Schachtebeck M, Schöbel A. Multi-stage recovery robustness for optimization problems: A new concept for planning under disturbances. Information Sciences. 2012;190: 107-126. 